Article

\title{
Aggregation State of Residual $\alpha$-Helices and Their Influence on Physical Properties of S. c. ricini Native Fiber
}

\author{
Kelvin O. Moseti ${ }^{1,2,3} \mathbb{C}$, Taiyo Yoshioka ${ }^{2}$, Tsunenori Kameda ${ }^{2, *}$ and Yasumoto Nakazawa ${ }^{1, *}$ (D) \\ 1 Department of Biotechnology and Life Science, Graduate School of Engineering, Tokyo University of \\ Agriculture and Technology, 2-24-16 Naka-cho, Koganei, Tokyo 184-8588, Japan; kelvinmoseti@gmail.com \\ 2 Silk Materials Research Unit, Institute of Agrobiological Sciences, National Agriculture and Food Research \\ Organization, 1-2 Owashi, Tsukuba, Ibaraki 305-8634, Japan; yoshiokat@affrc.go.jp \\ 3 National Sericulture Research Centre, Industrial Crops Research Institute, Kenya Agricultural and Livestock \\ Research Organization, P.O. Box 7816-01000 Thika, Kenya \\ * Correspondence: kamedat@affrc.go.jp (T.K.); yasumoto@cc.tuat.ac.jp (Y.N.); Tel.: +81-29-838-6213 (T.K.); \\ $+81-42-388-7612$ (Y.N.)
}

Academic Editor: Abbas Milani

Received: 10 September 2019; Accepted: 15 October 2019; Published: 17 October 2019

\begin{abstract}
Formation of the $\alpha$-helical conformation in the poly-L-alanine (PA) sequence regions, subsequent structural transition to $\beta$-sheet during natural spinning, and presence of residual $\alpha$-helices in Samia cynthia ricini (S. c. ricini) native silk fiber have been experimentally proven. However, the aggregation state of the residual $\alpha$-helices, and their influence on the mechanical deformation behavior in native fiber remain unclear. Here we show that the $\alpha$-helices form an ordered aggregation state with a hexagonal packing in the aqueous solution, some of which remain during natural spinning. X-ray scattering and differential scanning calorimetry (DSC) analyses revealed occurrence of a structural transition of the residual $\alpha$-helices to the $\beta$-sheet structure, accompanied by disappearance of the plateau region in the force-strain curve, due to heat-treatment at $\sim 220^{\circ} \mathrm{C}$. On the basis of X-ray scattering before and after tensile stretching of S. c. ricini native silk, a direct connection between the plateau region and the $\alpha$-helix to $\beta$-sheet structural transition was confirmed. Our findings demonstrate the importance of the PA sequence regions in fiber structure formation and their influence on the tensile deformation behavior of S. c. ricini silk, features believed to be essentially similar in other saturniid silks. We strongly believe the residual ordered $\alpha$-helices to be strategically and systematically designed by S. c. ricini silkworms to impart flexibility in native silk fiber. We anticipate that these knowledge forms a basis for fruitful strategies in the design and development of amino acid sequences for artificial silks with desired mechanical properties.
\end{abstract}

Keywords: S. c. ricini silk; polyalanine sequence; $\alpha$-helix; liquid fibroin; $\alpha$-helix to $\beta$-sheet transition

\section{Introduction}

Towards establishing a sustainable society, effective utilization of Saturniidae wild-silkworm silks is receiving increased attention because of their excellent material properties and abundant yields in nature [1]. Among them, silk produced by the semi-domesticated wild-silkworm, Samia cynthia ricini (S. c. ricini), is one of the most promising candidates. Its structure and mechanical properties have been well investigated, that is, the silk is one of the most studied among those obtained from non-mulberry sericulture [1,2]. Indeed, S. c. ricini silk fibroin (SF) is attracting increasing attention in diverse fields including the biomedical field as a source of biomaterials [3,4].

Earlier X-ray diffraction analyses classified S. c. ricini native fiber under group 3a, that is, they have a poly-L-alanine (PA) type $\beta$-sheet structure with an inter-sheet packing of $10.6 \AA$ [5]. 
With the advancement of sequencing technology, the primary structure of $S$. c. ricini SF has been clarified to typically comprise of alternating repeat PA, Ala (12-13), and Gly-rich sequence regions [1]. In contrast, that of the mulberry silkworm, Bombyx mori (B. mori) SF, mainly consists of a (GAGAGS)n repeat sequence $[6,7]$. This characteristic assembly in the primary structure of S. c. ricini SF is almost similar to that of SF derived from silks produced by other Saturniidae wild silkworms such as Antheraea pernyi (A. pernyi) [8,9], Antheraea yamamai (A. yamamai) [10], Antheraea assama (A. assama) [11] and Antheraea mylitta (A. mylitta) [12], as well as the major ampullate (MA) silk of spiders (although their PA sequences are shorter, $\left.\mathrm{Ala}_{(5-6)}\right)[13,14]$. Similar to the PA sequences in S. c. ricini and other native wild SF, X-ray diffraction, and infrared, Raman and solid-state NMR spectroscopy studies [15-24] have shown the (GAGAGS) $\mathrm{n}$ repeat sequence regions in B. mori silk SF to primarily contribute to the formation of $\beta$-sheets [17,19-21,25,26]. In addition, the two kinds of SF have other structures such as $\alpha$-helix and random coil [21,27].

The heterogeneous nature of SF is believed to influence the fiber structure and mechanical performance of silks. Consequently, variability in mechanical properties of silks has been closely linked to the differences in primary, secondary and hierarchical structures of SF [21,28,29]. For instance, B. mori and S. c. ricini silks have $\beta$-sheet structures but exhibit distinct mechanical properties; $S$. c. ricini native fiber exhibit a characteristic plateau region in their stress-strain curve unlike that from $B$. mori that show a distinct yielding point [21,28-30]. This unique feature, also observed in other wild silks [21,29], is often interpreted to be a result of some structural transitions, such as helical to zigzag conformations in poly(ethylene oxide) [31], $\alpha$-helix to $\beta$-sheet conformations in keratin [32,33], and amorphous to crystalline states in natural rubber [34]. Since the predominant feature in saturniid fibroin sequences is the highly repetitive PA and Gly-rich regions, the phenomenon was also recently hypothesized to reflect co-ordinated molecular movement that may arise from the high degree of regularity [29].

Studies on the structural formation of S. c. ricini silk have widely been performed using silk dope from the posterior silk glands (PSG) of mature larvae. Based on ${ }^{13} \mathrm{C}$ solid-state NMR spectroscopy, a film cast from liquid fibroin (LF) solution has been clarified to have a $\alpha$-helical conformation $[22,35,36]$, the amino acid component in the $\alpha$-helix being dominantly from the PA regions [37]. The structural transition from $\alpha$-helix to $\beta$-sheet during stretching of semi-dried silk dope [16], considered to correspond to the natural spinning process [22], was traced by ${ }^{13} \mathrm{C} \mathrm{CP-MAS,} \mathrm{X-ray} \mathrm{diffraction} \mathrm{and}$ Raman spectroscopic analyses [16]. Further, Asakura et al. revealed that some amount of the $\alpha$-helical conformation remains even in the native S. c. ricini fiber [38]. However, the aggregation state of the $\alpha$-helices in the native fiber is yet to be clarified.

In this study, we try to clarify (a) the aggregation state of residual $\alpha$-helices in S. c. ricini native fiber, (b) whether they transform to $\beta$-sheets during stretching, (c) the effect on the physical properties of the fiber if the structural transformation occurs, and (d) if complete transformation of the residual $\alpha$-helices can be attained. To achieve these, two kinds of samples were prepared as summarized in Scheme 1. (1). Silk dope was obtained from the PSG of mature larvae and diluted to give an aqueous solution of LF from which cast films were prepared (herein referred to as $\mathrm{LF}_{\mathrm{aq}}$ as-cast films; refer to Section 3.1). (2). Native fibers were obtained from cocoons spun by larvae from the same batch from which the silk dope was obtained. Detailed comparative structural analyses of the silk samples were carried out by ${ }^{13} \mathrm{C}$ CP-MAS solid-state NMR spectroscopy, Fourier transform infra-red spectroscopy (FTIR), wide angle X-ray diffraction (WAXD), thermal gravimetry (TG), and differential scanning calorimetry (DSC). Our results revealed that the residual $\alpha$-helices in S. c. ricini native silk aggregate with a hexagonal packing and their strong contribution to the characteristic fiber physical properties was clarified. 


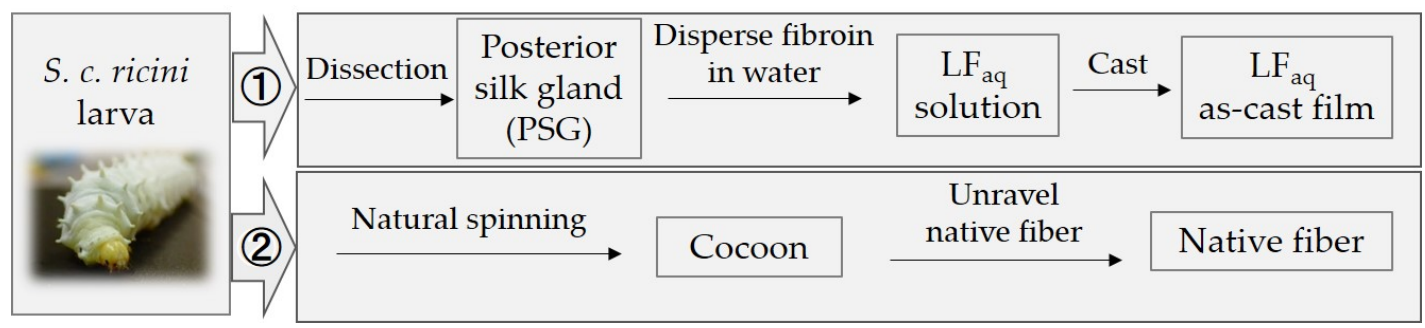

Scheme 1. A summary of the schemes used in preparation of the S. c. ricini $\mathrm{LF}_{\mathrm{aq}}$ as-cast film (route (1)) and native fiber (route (2) samples.

\section{Results and Discussion}

\subsection{Ordered $\alpha$-Helix Structure in S. c. ricini Liquid Fibroin As-Cast Film}

Silk dope collected from the PSG of mature S. c. ricini larvae was diluted with milli-Q water to give a transparent aqueous solution of $\mathrm{LF}\left(\mathrm{LF}_{\mathrm{aq}}\right)$. Films cast from this solution ( $\mathrm{LF}_{\mathrm{aq}}$ as-cast films) at $23 \pm 2{ }^{\circ} \mathrm{C}$ and a relative humidity of $30 \pm 2 \%$, were transparent and flexible. Secondary structure of bio-polymers obtained over a broad spectral range may be handy in understanding and predicting their properties and potential applications [39]. However, in the current study, we focus on the aggregation state of the $\alpha$-helical domains in the $\mathrm{LF}_{\mathrm{aq}}$ as-cast film and native fiber, and clarification of such spectral features remains an important and interesting topic for future studies [40]. ${ }^{13} \mathrm{C} \mathrm{CP}-\mathrm{MAS}$ NMR spectra of the $\mathrm{LF}_{\mathrm{aq}}$ as-cast film and native fiber are shown in Figure 1. The chemical shift assignments for the Ala $C_{\beta}$, Gly $C_{\alpha}$, Ala $C_{\alpha}$ and $C=O$ spectral regions used in the current report are indicated in the spectra $[16,21,24]$. The native silk fiber was $\beta$-sheet-rich whereas the $L_{\text {aq }}$ as-cast film was $\alpha$-helix-rich. These results are consistent with previous work [12,22], since S. c. ricini LF is known to have a well-structured $\alpha$-helical conformation in the PA region [27]. This result was well supported by FTIR as shown in the typically $\alpha$-helix-rich FTIR spectrum of the LF $_{\text {aq }}$ as-cast film in Figure 2. The amide I region of the spectrum is assigned to the $\alpha$-helical conformation whereas, the amide II region seems to contain a small amount of $\beta$-sheet or other components.

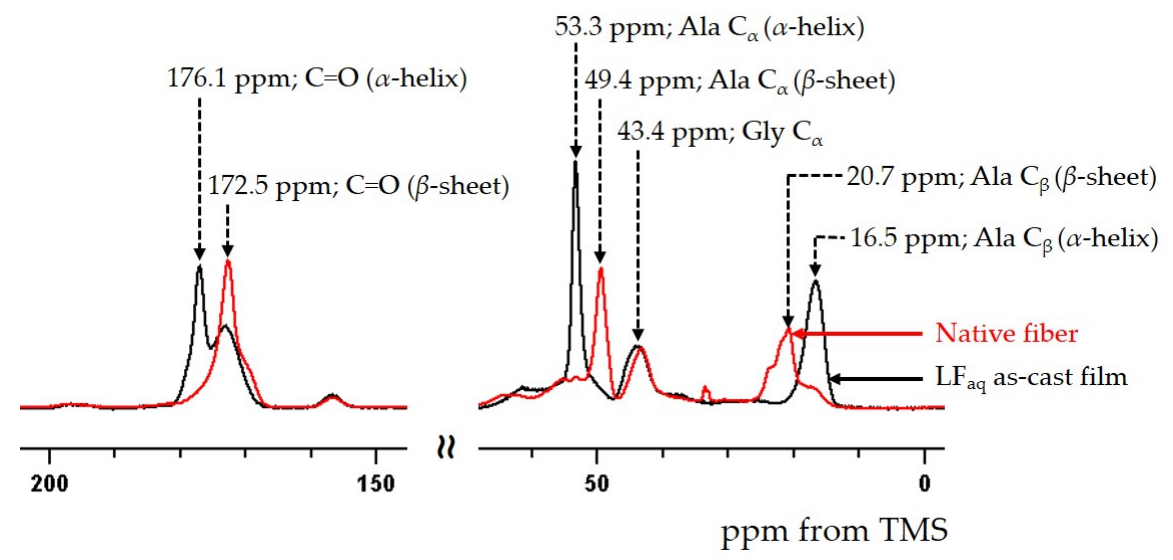

Figure $1 .{ }^{13} \mathrm{C}$ CP-MAS solid-state NMR spectra of S. c. ricini $\mathrm{LF}_{\mathrm{aq}}$ as-cast film (spectrum in black) and native silk fiber (spectrum in red) from 0 to 60 , and 150 to $200 \mathrm{ppm}$. 


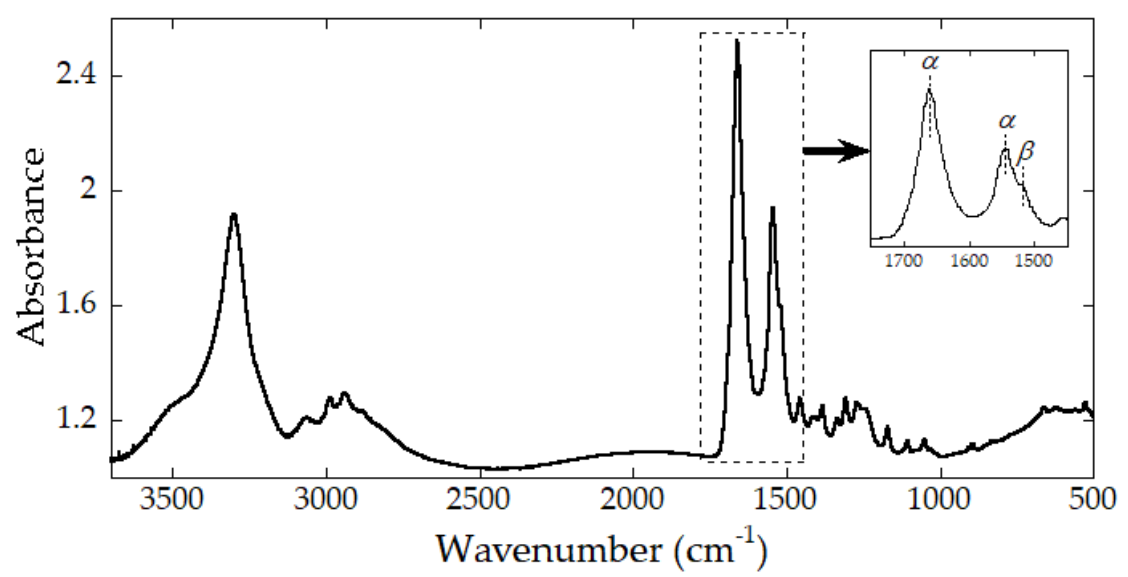

Figure 2. A representative FTIR spectrum of S. c. ricini $\mathrm{LF}_{\mathrm{aq}}$ as-cast film. Inset is the spectrum showing the vibrational bands in the amide I and II regions.

A WAXD 2 $\theta$-profile of the $\mathrm{LF}_{\mathrm{aq}}$ as-cast film is shown in Figure 3. A strong and sharp peak at $2 \theta=11.6^{\circ}$ (corresponding to $d=7.6 \AA$ ), a broad peak having an undefined peak-top at around $2 \theta=22.7^{\circ}$ (corresponding to $d=3.9 \AA$ ) as well as a distinct small-angle scattering peak at $2 \theta=2.7^{\circ}$ (corresponding to $d=32.7 \AA$ ) were detected. Similar peak combinations of the former two were observed for dried LF dopes of S. c. ricini [16] and A. pernyi [35,36] and assigned to the $\alpha$-helix structure. Based on X-ray structural analysis of a highly-oriented crystalline $\alpha$-helix sample of PA, Bamford et al. determined a hexagonal unit cell $(a=8.55 \AA)$, giving a strong diffraction of the (10-10) plane at $d_{10-10}$ $=7.40 \AA$ [41]. A slightly lager $d$-spacing of the (10-10) plane indicates a slightly larger hexagonal unit cell dimension, probably affected by side chains of amino acid residues neighboring the PA sequence regions. The unclear broad peak at around $3.9 \AA$ as well as the other similar observation in the abovementioned work on dried LF dopes from S. c. ricini and A. pernyi strongly suggest that the $\alpha$-helical domains are aggregated with a hexagonal packing, but not perfectly crystallized as observed in PA [41] and poly- $\gamma$-methyl-L-glutamate [42]. The ordered aggregation size along the (10-10) lattice direction (roughly corresponding to the diameter of the cross-sectional area of the aggregated $\alpha$-helices bundle) was evaluated from the peak width of the (10-10) peak using the Scherrer equation to be $32 \AA$. This dimension is well consistent with the small-angle scattering corresponding to a periodicity of $32.7 \AA$, suggesting that the aggregated $\alpha$-helices bundles further form a hierarchical super-array with a neighboring distance of around $32-33 \AA$.

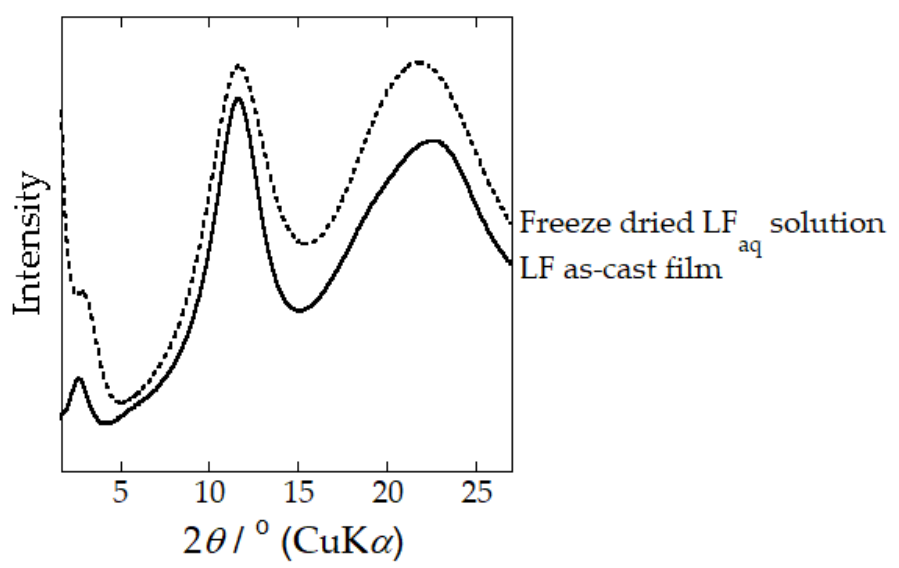

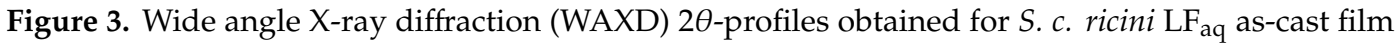
(solid line profile) and a freeze-dried sample of the LF solution from which the film was cast (dotted line profile). 
From the X-ray analyses, it is evident that the fibroin molecules in the $\mathrm{LF}_{\mathrm{aq}}$ as-cast film assemble into an ordered aggregated structure. To clarify the stage during which structural formation of the ordered $\alpha$-helices occurs, WAXD analysis of a freeze-dried sample, frozen at $-80^{\circ} \mathrm{C}$, of the LF-solution from which the $\mathrm{LF}_{\mathrm{aq}}$ film was cast, was performed. The WAXD $2 \theta$-profile of the freeze-dried sample, shown in Figure 3, was essentially similar to that of the $\mathrm{LF}_{\mathrm{aq}}$ as-cast film. Considering previous work showing successful immobilization of the structure of SF by freezing at $-80^{\circ} \mathrm{C}[43,44]$, our experimental result strongly indicates the existence of the ordered aggregated structure in the aqueous state. This is consistent with a common consensus in natural spinning of spider silks [45] and B. mori silkworm silk $[46,47]$, in which LF comes out of the spinneret in a liquid crystalline or nematic state. The formation of an ordered aggregation state in the $\alpha$-helical domains in the solution state of S. c. ricini seems quite reasonable to achieve efficient natural spinning, during which highly oriented and crystalline fiber is produced with consumption of minimum energy.

Figure 4 shows the TG and DSC profiles of the $\mathrm{LF}_{\mathrm{aq}}$ as-cast film, and native and heat-treated S. c. ricini silk fiber. As seen in Figure $4 \mathrm{a}, \mathrm{d}$, a remarkably sharp exothermic peak, speculated to correspond to a structural transition from the ordered aggregated $\alpha$-helix to $\beta$-sheet structure, was detected at $\sim 220^{\circ} \mathrm{C}$ in the DSC profile of the $\mathrm{LF}_{\mathrm{aq}}$ as-cast film.

(a)

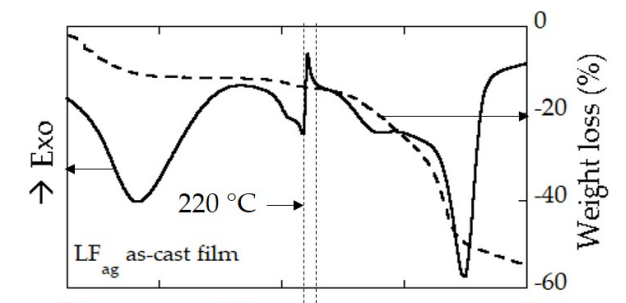

(b)

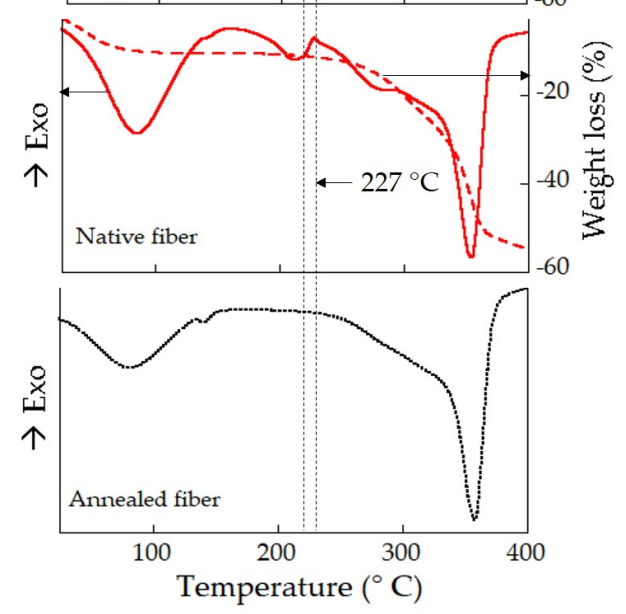

(d)

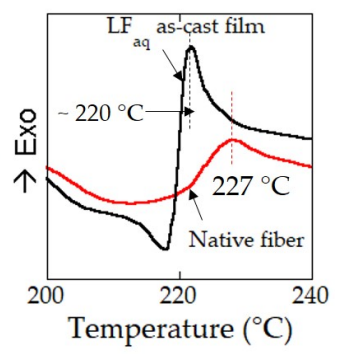

Figure 4. Thermal gravimetry (TG) and differential scanning calorimetry (DSC) profiles of S. c. ricini $\mathrm{LF}_{\mathrm{aq}}$ as-cast film (a), and native $(\mathbf{b})$, and heat-treated $\left(220^{\circ} \mathrm{C}, 1 \mathrm{~min} ; \mathbf{c}\right)$ fibers. Panel $\mathbf{d}$ shows a comparison of the $\mathrm{LF}_{\mathrm{aq}}$ as-cast film (profile in black) and native silk fiber (profile in red) DSC profiles between 200 and $240{ }^{\circ} \mathrm{C}$.

To clarify the kind of transition that occurs, as-cast and heat-treated $\left(220^{\circ} \mathrm{C}, 1 \mathrm{~min}\right) \mathrm{LF}_{\mathrm{aq}}$ films were subjected to WAXD analysis. WAXD $2 \theta$-profiles of native fibers (same profile shown in Figure 3), and the as-cast and heat-treated $\mathrm{LF}_{\mathrm{aq}}$ film are shown in Figure 5. A clear transition from the ordered aggregated $\alpha$-helix to $\beta$-sheet structure, induced by heat treatment, was confirmed. Such a narrow temperature window in the structural transition in the $\mathrm{LF}_{\mathrm{aq}}$ as-cast film (Figure $4 \mathrm{a}, \mathrm{d}$ ) is considered to result from instantaneous solid-to-solid phase transition from the hexagonally packed $\alpha$-helix to the $\beta$-sheet structure with minimum molecular movement. 


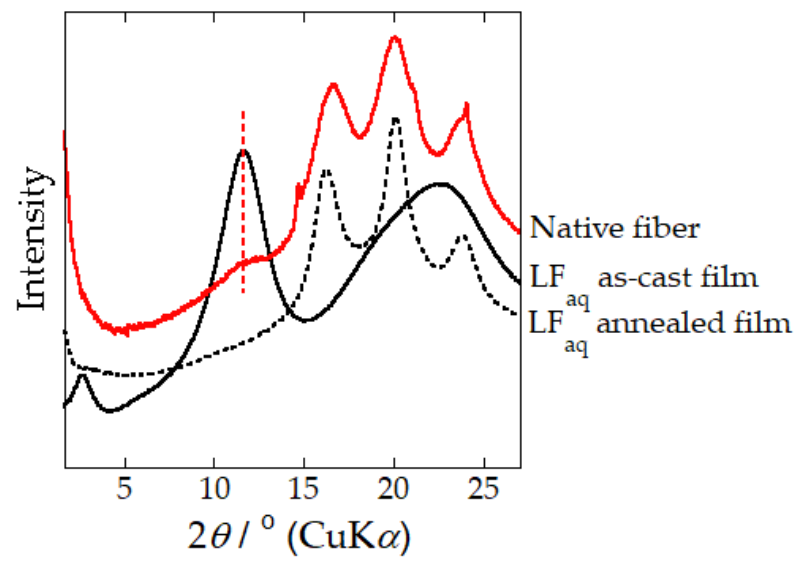

Figure 5. WAXD 2 $\theta$-profiles of native S. c. ricini silk fiber (profile in red), and as-cast (profile in black solid line) and heat-treated $\left(220^{\circ} \mathrm{C}, 1 \mathrm{~min}\right.$; profile in black dotted line) $\mathrm{LF}_{\mathrm{aq}}$ cast films.

\subsection{Ordered $\alpha$-Helix Structure in S. c. ricini Native Silk Fiber}

Although the WAXD $\beta$-sheet profile of the heat-treated $\mathrm{LF}_{\mathrm{aq}}$ cast film was essentially similar to that of the typically $\beta$-sheet-rich native S. c. ricini silk fiber (Figure 5), a small but highly reproducible difference existed: A shoulder peak in the native silk fiber profile (indicated by the dotted red line) corresponding to the peak assigned to the ordered aggregated $\alpha$-helix structure in the $\mathrm{LF}_{\mathrm{aq}}$ as-cast film in the preceding section was detected. We speculated the peak to indicate the presence of a small amount of residual ordered aggregated $\alpha$-helix structure in the native fiber. This speculation was supported by the DSC results of native fiber in which a peak similar to the characteristic sharp exothermic peak in the DSC profile of $\mathrm{LF}_{\mathrm{aq}}$ as-cast film was detected (Figure $4 \mathrm{~b}$ ). However, in the DSC profile of native fiber, the exothermic peak was broad and had a slightly higher peak top temperature $\left(\sim 227^{\circ} \mathrm{C}\right)$. Moreover, the endothermic peak was reversed, that is, it appeared at a slightly lower temperature (Figure $4 \mathrm{~d}$ ).

To account for the residual ordered $\alpha$-helices detected in the native silk fiber, it is considered that aggregated domains with higher ordering level preferentially transform to $\beta$-sheets during natural spinning, whereas those with a lower ordering level are not. In other words, the ordered aggregated $\alpha$-helix in native S. c. ricini fiber is considered to be partially collapsed and has a slightly unstable structure. Hence, the structural transition (endothermic reaction) starts at a slightly lower temperature in the fiber than in the as-cast film. Often, the $\beta$-sheet structure is difficult to form, hence, subsequent $\beta$-sheet formation does not occur until a higher temperature is attained. For instance, in the assembled portion of amino acids where side chains are bulky, larger molecular motion (higher energy) is required because they hinder $\beta$-sheet formation, hence the exothermic peak occurs at a higher temperature. This implies that, sites where $\beta$-sheet formation is relatively difficult that are untransformed during native spinning exist in the ordered aggregated $\alpha$-helix structure. Further, partial collapse of the originally ordered structure that results in broadening of the transition peak in native silk fiber is considered to result from stretching and compression during spinning. The presence of the structure that does not easily transform to $\beta$-sheet may be considered intentional and a strategy of the S. c. ricini silkworms to impart flexibility in the silk.

To clarify if the peak could not be ascribed to $\beta$-sheet but the ordered aggregated $\alpha$-helix structure, native silk fibers were heat-treated as previously discussed for the as-cast $L_{\mathrm{aq}}$ film and subjected to WAXD and DSC analyses. WAXD $2 \theta$-profiles of native (same profile shown in Figure 5) and heat-treated silk fibers are shown in Figure 6. Consistent with our earlier results for the heat-treated $\mathrm{LF}_{\mathrm{aq}}$ film, the peak disappeared accompanied by enhancement of the intensity of the peaks assigned to $\beta$-sheet structure. Similar disappearance of the exothermic peak in the DSC profile for heat-treated fibers was observed (Figure 4c). These results confirm that though low in abundance, native S. c. ricini silk fibers contain an ordered aggregated $\alpha$-helix structure. 


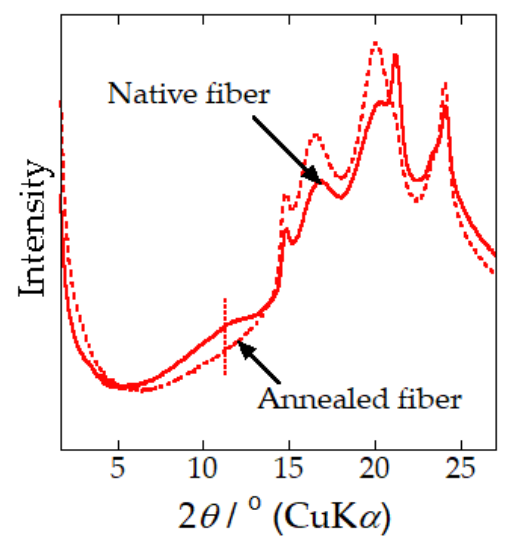

Figure 6. WAXD 2 $\theta$-profiles of native (profile in red solid line) and heat-treated $\left(220^{\circ} \mathrm{C}, 1 \mathrm{~min}\right.$; profile in red dotted line) S. c. ricini fibers.

\subsection{Impact of Heat-Treatment on the Mechanical Properties of Single S. c. ricini Native Fiber}

In the preceding section, we successfully detected a signal peak of residual ordered aggregation of $\alpha$-helices in the WAXD pattern of S. c. ricini native silk fiber. The residual helices were confirmed to transform into $\beta$-sheet due to heat-treatment at around $220^{\circ} \mathrm{C}$ by WAXD and DSC. Moreover, it is well established that stretching induces $\alpha$-helix to $\beta$-sheet structural transition in various types of silks including S. c. ricini LF-based materials [16,18], spider [48], and regenerated B. mori [47] silk. However, the relationship between this structural transition and the characteristic plateau deformation behaviour in the stress-strain curve of S. c. ricini native fibers remains unclear. To clarify the relationship, the effect of heat-treatment on the plateau phase in the stress-strain curve of single $S$. c. ricini native silk fibers was investigated. The cross-sectional areas of native silk fiber has been shown to vary along the silk fiber axis [29], due to flaws possibly associated with the larvae's spinning behaviour [49] often affected by among other factors, temperature and relative humidity [50]. Hence, since the cross-sectional areas of the individual test fibers were not evaluated in the current study, fiber sampled from adjacent portions of single fiber carefully unravelled from the middle layer of the middle part of the cocoon were used for the tensile tests before and after heat-treatment, respectively, to reduce variability. Therefore, the mechanical properties discussed here are an estimation from the representantive force $(\mathrm{N})$ against strain (\%) plots. Further, the heat-treatment temperature was chosen based on the DSC data discussed in preceding section, where $\alpha$ to $\beta$-sheet structural transition was confirmed, under a similar heat-treatment regime for native fiber (cocoon sections) used for WAXD analyses.

The results of the tensile tests of native and heat-treated S. c. ricini silk single fibers were reproducible, and representative stress-strain curves are shown in Figure 7. As expected, a distinct plateau region was detected in the stress-strain curve of native silk fiber, but was absent or significantly diminished in the stress-strain curve of the heat-treated fiber. Further, the stress-strain curve of the heat-treated single fibers transformed to be like that of B. mori and exhibited a lower strain to break (extensibility). The disappearance of the plateau phase and lower extensibility were speculated to be due to $\alpha$ to $\beta$-sheet structural transition, caused by the heat-treatment (see Figure 7), already clarified in the preceding section. This is because heat-treatment reduces the residual $\alpha$-helices (increases the $\beta$-sheet content) in the fibers which often results in enhanced stiffness [51]. In the current study, the fiber spinning process has been shown to play a key role in determining the unique material properties of S. c. ricini native fibers, in addition to the highly repetitive SF protein amino acid sequence in various silks recently reported by Malay et al. [29]. 


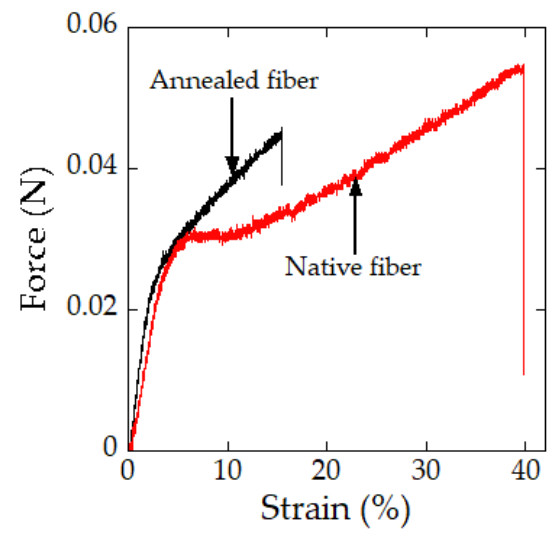

Figure 7. Representative force-strain curves of native (curve in red), and heat-treated $\left(220^{\circ} \mathrm{C}, 1 \mathrm{~min}\right.$; curve in black) S. c. ricini single silk fibers.

\subsection{Strain-Dependent $\alpha$-Helix to $\beta$-Sheet Transition in S. c. ricini Native Silk Fiber Traced by WAXD}

To investigate the relationship between the plateau deformation behavior and the residual $\alpha$-helix to $\beta$-sheet structural transition, WAXD measurements of a parallel-aligned bundle of $S$. c. ricini native fibers were performed at three different stages; before stretching (intact fiber-bundle; (1), just after the plateau region (3), and after fiber bundle breaks (6). As depicted in Figure 8a, stretching was paused just after the plateau region, corresponding to $\varepsilon=16 \%$ (indicated by arrow (2). This was immediately followed by a rapid drop in force, corresponding to stress relaxation, as seen beyond point (2). The second WAXD measurement was started after the stress relaxation was almost saturated as indicated by arrow (3). Due to inter-strand hydrogen bonding, $\beta$-sheets are energetically favorable, that is, they are high-temperature relaxed structures [52] and the structural transition from $\alpha$-helix to $\beta$-sheet is irreversible. Hence, the influence of stress relaxation on the purpose of this WAXD measurement, that is, to trace the changes of the signal peak of ordered aggregation of $\alpha$-helices, was considered negligible.
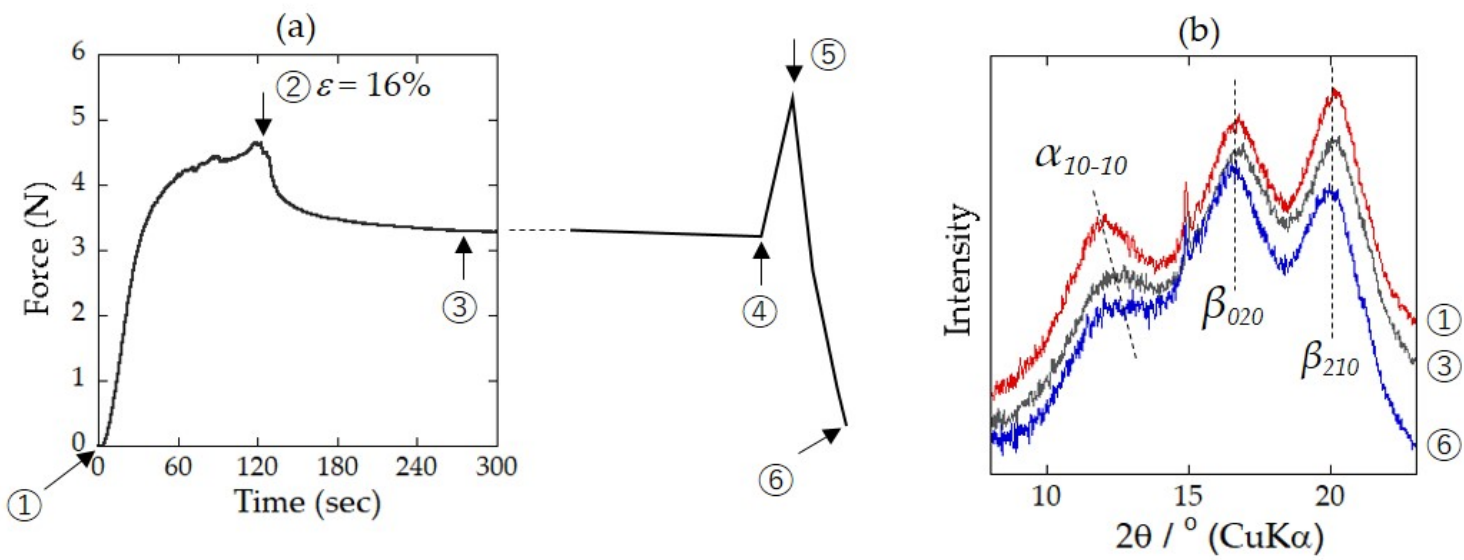

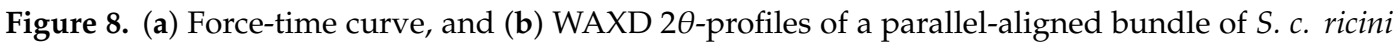
native fiber before stretching (1) (profile in red), just after the plateau region ( $\varepsilon=16 \%$; (3); profile in black), and after the fiber bundle broke (6) (profile in blue).

After the second WAXD measurement, the fiber bundle was again stretched (indicated by arrow (4) until it broke (indicated by arrows (5) and (6)). This was followed by a third WAXD measurement (6), without distorting the broken but parallel-aligned fiber bundle on the Linkam tensile stage. The equatorial 2 $\theta$-profiles scanned from the resultant WAXD patterns were as shown in Figure $8 \mathrm{~b}$. In addition to the equatorial (020) and (210) $\beta$-sheet reflections, the signal reflection of the (10-10) ordered residual $\alpha$-helices was clearly detected in intact native fiber. This peak was observed to decrease gradually with increasing strain. A significant decrease in the peak intensity of this signal 
reflection was observed after the fiber bundle broke; however, the decrease majorly occurred before the end of the plateau region. This observation suggests $\beta$-sheet formation to occur at the expense of the $\alpha$-helix structure.

\section{Experimental Section}

\subsection{Preparation of S. c. ricini $L F_{a q}$ As-Cast Film and Native Fiber}

S. c. ricini silkworm larvae were reared in the laboratory on an all-instar artificial diet, SilkMate L4M (Nosan Corp., Yokohama, Japan) at $25 \pm 3{ }^{\circ} \mathrm{C}$ and a relative humidity of $65 \pm 3 \%$. Late 5 th instar larvae, just after gut purging, were anaesthized in ice for $15 \mathrm{~min}$ and dissected to obtain intact silk glands. The silk glands were briefly rinsed in cold Milli-Q water $\left(\sim 4{ }^{\circ} \mathrm{C}\right)$ and silk dope in the lumen of the PSG was drained into cold Milli-Q water and carefully rinsed by exchanging the Milli-Q water several times to remove any contaminants. The thus-obtained silk dope was diluted with Milli-Q water to give an aqueous solution of fibroin, herein referred to as liquid fibroin $\left(\mathrm{LF}_{\mathrm{aq}}\right)$, that was gently cast on polystyrene Petri-dishes. After drying at $23 \pm 2{ }^{\circ} \mathrm{C}$ and a relative humidity of $30 \pm 2 \%$ [46], transparent and flexible films that could be peeled off the substrate with negligible mechanical damage were obtained. The thickness of the cast films was controlled by adjusting the concentration or volume of LF cast.

For comparison, some S. c. ricini larvae from each batch reared (from which the LF used in the preparation of the as-cast films was obtained) were let to spin cocoons whence native fibers analysed was obtained as described in the subsequent sections.

\section{2. ${ }^{13}$ C Cross Polarization-Magic Angle Spinning (CP/MAS) Solid-State NMR Spectroscopy}

${ }^{13} \mathrm{C} C \mathrm{CP} / \mathrm{MAS}$ solid-state NMR measurements were performed with a Bruker Avance $600 \mathrm{WB}$ (Karlsruhe, Germany) spectrometer with a magnetic field of $14.1 \mathrm{~T}$ at room temperature. The spectrometers were operated at a ${ }^{13} \mathrm{C}$ NMR frequency of $150.94 \mathrm{MHz}$. For each measurent, the fibroin protein sample was cut into small pieces, packed into a solid-state probe, and spun at a MAS frequency of $10.0 \mathrm{kHz}$ in a $4.0 \mathrm{~mm} \varnothing$ zirconia rotor sample tube. $\mathrm{A}^{1} \mathrm{H} 90^{\circ}$ pulse length of $3.5 \mu \mathrm{s}$ and ${ }^{1} \mathrm{H}-{ }^{13} \mathrm{C}$ cross-polarization (CP) contact of $70 \mathrm{kHz}$ were employed for the $\mathrm{CP}$ experiments. High-power ${ }^{1} \mathrm{H}$ decoupling using the SPINAL-64 method was employed. The repetition time for the CP experiments was $3.0 \mathrm{~s}$ and the ${ }^{13} \mathrm{C}$ chemical shifts were calibrated externally through the adamantane methylene peak at $29.5 \mathrm{ppm}$ relative to TMS at $0 \mathrm{ppm}$. For native fiber, cocoon sections analysed were sampled from the middle section of the middle layer of the cocoons obtained in sub-Section 3.1.

\subsection{Fourier Transform Infrared (FTIR) Spectroscopy}

Since amide vibrations depend on the secondary structure of proteins, FTIR spectroscopy is often used in studying the secondary structures of proteins. In the current study, FTIR measurements of the $\mathrm{LF}_{\mathrm{aq}}$ as-cast films were recorded at room temperature with an FTIR-620 (JASCO International Co. Ltd., Hachioji-shi, Japan) spectrometer in the transmission mode. For each measurement, 32 scans were co-added in the spectral range 4000 to $400 \mathrm{~cm}^{-1}$ with a $2 \mathrm{~cm}^{-1}$ resolution. The resultant spectrum was corrected by subtracting a background spectrum recorded under similar scan conditions. The assignments of conformation sensitive bands for S. c. ricini SF used in this report were: $\sim 1625$ and $\sim 1519 \mathrm{~cm}^{-1}$ as $\beta$-sheet structure [21,53] and $\sim 1658$ and $1545-1548 \mathrm{~cm}^{-1}$ as $\alpha$-helix $[12,53]$.

\subsection{Wide-Angle X-ray Diffraction Analyses}

To clarify the aggregation state of the $\alpha$-helical domains in the $\mathrm{LF}_{\mathrm{aq}}$ as-cast film and native fiber, WAXD measurements were carried out with a $3.5 \mathrm{~m}$ NANOPIX X-ray diffractometer (Rigaku Corp., Tokyo, Japan) $\left(40 \mathrm{kV}, 30 \mathrm{~mA}, \mathrm{Cu}-\mathrm{K}_{\alpha}\right.$ radiation $\left.(\lambda=1.5418 \AA)\right)$ equipped with a highly sensitive single-photon counting pixel HyPix-6000 2D detector with a pixel size of $100 \times 100 \mu \mathrm{m}^{2}$ (Rigaku Corp., Tokyo, Japan) as earlier described [54]. Calibration of the camera distance was carried out using cerium 
oxide powder and a background diffraction pattern collected under conditions similar to those used for sample analysis was subtracted from each measurement. To obtain the WAXD $2 \theta$-profile of LF, an aliquot of the solution was rapidly frozen to $-80{ }^{\circ} \mathrm{C}$ in an ultra-low temperature Nihon freezer (NF-10SF3, Tokyo, Japan) and lyophilized in an EYELA vacuum freeze-dryer (FDU 830, Tokyo, Japan) for $24 \mathrm{~h}$. The crystallite sizes were evaluated on the basis of the Scherrer equation. For the heat-treated $\mathrm{LF}_{\mathrm{aq}}$ film and native fiber (sampled from the middle layer of the middle section of cocoons obtained in sub-Section 3.1), the samples were cut into small pieces each about $0.5 \times 0.5 \mathrm{~mm}$ and separately sandwiched between thin glass slides ( $1.0 \mathrm{~mm}$ thick), alongside a thin and sensitive thermocouple to monitor the sample temperature directly. These were set on a digital hot-plate (Corning PC-420D), heated to $220^{\circ} \mathrm{C}$, and kept at this temperature (annealed) for about $1 \mathrm{~min}$ and allowed to cool to room temperature.

\subsection{Thermal Analyses}

Differential scanning calorimetry (DSC) measurements were performed with a DSC Q200 analysis system (TA Instruments, New Castle, DE, USA). Instrument calibration for heat flow and temperature were done using indium, whereas for heat capacity, aluminum and sapphire were used. For each measurement, about $5.0 \mathrm{mg}$ of the fibroin protein sample was encapsulated in an aluminum pan and heated between -30 and $430{ }^{\circ} \mathrm{C}$ at $2{ }^{\circ} \mathrm{C} \mathrm{min}^{-1}$ under a dry nitrogen gas flow of $50 \mathrm{~mL} \mathrm{~min}^{-1}$.

The concentrations of LF, and the weight loss profiles of the $\mathrm{LF}_{\mathrm{aq}}$ as-cast film and native fiber were determined by thermal gravimetry (TGA) with a Thermoplus TG 8120 system (Rigaku Corp., Tokyo, Japan). For each measurement, about $1.0 \mathrm{mg}$ of the fibroin protein was heated in an aluminium pan from room temperature to $430{ }^{\circ} \mathrm{C}$ at a heating rate of $2{ }^{\circ} \mathrm{C} \mathrm{min}-1$ under a dry nitrogen gas flow of $200 \mathrm{~mL} \mathrm{~min}{ }^{-1}$.

\subsection{Tensile Tests of Single S. c. ricini Silk Fibers}

Tensile properties of S. c. ricini single fibers were measured using an EZ Test/CE mechanical stage (Shimadzu Co., Kyoto, Japan) equipped with a $5 \mathrm{~N}$ load cell. All tests were carried out in the dry state at $23 \pm 2{ }^{\circ} \mathrm{C}$, and a relative humidity of $37 \pm 2 \%$. Single fibers, each approximately $6.0 \mathrm{~cm}$, were carefully unravelled from the middle section of the middle layer of the native cocoons obtained in sub-Section 3.1, sub-divided and labelled systematically (say A and B, for native and heat-treated tests, respectively). One set of the fibers were set using a kapton tape and sandwiched between thin glass slides ( 1.0 mm thick), alongside a thin and sensitive thermocouple and heat-treated as described in sub-Section 3.4. Each fiber (native and heat-treated) was then mounted without pre-load onto rectangular paper frames with an initial gauge length of $15 \mathrm{~mm}$ and their tensile deformation behaviour was evaluated at a cross-head speed of $2 \mathrm{~mm} \mathrm{~min}^{-1}$. The tensile properties reported were averaged from three measurements, each for native and heat-treated fiber. A paired $t$-test using GraphPadPrism 5 (GraphPad Software, Inc., San Diego, CA, USA) was used to compare native and heat-treated data at $95 \%$ confidence interval.

\subsection{Strain-Dependent Structure Transformation Monitored by WAXD}

To monitor structural changes in S. c. ricini native fiber during tensile deformation, a parallel-aligned bundle, with a thickness of about $0.5 \mathrm{~mm}$, was carefully prepared from single fibers obtained from the cocoons as already described [54]. The fiber bundle was fixed on a mechanical tensile stage (Linkam Scientific Instruments, Epsom, Tadworth, UK) with a $3.0 \mathrm{~mm} \varnothing$ hole for the X-ray beam to pass through. The micro-stretcher was equipped with a $10 \mathrm{~N}$ load cell and coupled to the 3.5 m NANOPIX X-ray diffractometer (Rigaku Corp., Tokyo, Japan) (see sub-Section 3.4). The gauge distance was $20 \mathrm{~mm}$ and tensile deformation of the fiber bundle was carried out at a cross-head speed of $2 \mu \mathrm{m} \mathrm{sec}^{-1}$. WAXD measurements were carried out at three stages, that is, before stretching, just after the plateau region, and after the fiber bundle breaks. The duration of exposure for each WAXD measurement was $30 \mathrm{~min}$. 


\section{Conclusions}

The broad peak at around $3.9 \AA$ in the $2 \theta$-profiles of the $L_{\mathrm{aq}}$ as-cast film and native fibers revealed that the residual $\alpha$-helical domains in the otherwise typically $\beta$-sheet-rich native fiber are aggregated in a hexagonal packing. X-ray scattering and DSC revealed transformation of the residual $\alpha$-helices to $\beta$-sheets due to heat-treatment at $\sim 220^{\circ} \mathrm{C}$. The structural transition was accompanied by disappearance of the characteristic plateau region in the force-strain curve of the native fibers. Further, based on WAXD results before and after tensile deformation of the native fiber, we successfully elucidated the structural change occurring in the plateau region to be $\alpha$-helix to $\beta$-sheet. Our findings clearly demonstrate the fiber formation process (natural spinning) to be critical in determining the physical properties of native S. c. ricini fibers, that is, the larvae by design keep some $\alpha$-helices untransformed to impart flexibility in the native silk.

Author Contributions: Y.N., T.K., T.Y. and K.O.M. conceived and designed the experiments; K.O.M. and T.Y. performed the experiments, and analyzed the data; K.O.M. wrote the paper under the supervision of Y.N., T.K. and T.Y.

Funding: This research was supported by the Japan Science and Technology Agency (JST) and Japan International Cooperation Agency (JICA), Science and Technology Research Partnership for Sustainable Development (SATREPS) 2016-2021, grant number 18-161011166.

Acknowledgments: The authors are grateful to the staff of the Silk Materials Research Unit (NARO) for their kind support in rearing of S. c. ricini silkworms. We also thank the reviewers for their valuable comments and suggestions.

Conflicts of Interest: The authors declare no conflict of interest.

\section{References}

1. Zethner, O.; Koustrup, R.; Nguku, E.; Raina, S.K. African ways of silk, 2nd ed.; Regal Press Kenya Ltd.: Nairobi, Kenya, 2017.

2. Sezutsu, H.; Yukuhiro, K. The complete nucleotide sequence of the Eri-silkworm (Samia cynthia ricini) fibroin gene. J. Insect Biotechnol. Sericology 2014, 83, 59-70. [CrossRef]

3. Silva, S.S.; Oliveira, N.M.; Oliveira, M.B.; da Costa, D.P.S.; Naskar, D.; Mano, J.F.; Kundu, S.C.; Reis, R.L. Fabrication and characterization of Eri silk fibers-based sponges for biomedical application. Acta Biomater. 2016, 32, 178-189. [CrossRef] [PubMed]

4. Dutta, S.; Talukdar, B.; Bharali, R.; Rajkhowa, R.; Devi, D. Fabrication and characterization of biomaterial film from gland silk of Muga and Eri silkworms. Biopolymers 2013, 99, 326-333. [CrossRef] [PubMed]

5. Warwicker, J.O. Comparative studies of fibroins: II. The crystal structures of various fibroins. J. Mol. Biol. 1960, 2, 350-362. [CrossRef]

6. Zhou, C.Z.; Confalonieri, F.; Medina, N.; Zivanovic, Y.; Esnault, C.; Yang, T.; Jacquet, M.; Janin, J.; Duguet, M.; Perasso, R.; et al. Fine organization of Bombyx mori fibroin heavy chain gene. Nucleic Acids Res. 2000, 28, 2413-2419. [CrossRef] [PubMed]

7. Zhou, C.Z.; Confalonieri, F.; Jacquet, M.; Perasso, R.; Li, Z.G.; Janin, J. Silk fibroin: Structural implications of a remarkable amino acid sequence. Proteins 2001, 44, 119-122. [CrossRef]

8. Yukuhiro, K.; Kanda, T.; Tamura, T. Preferential codon usage and two types of repetitive motifs in the fibroin gene of the Chinese oak silkworm, Antheraea pernyi. Insect Mol. Biol. 1997, 6, 89-95. [CrossRef]

9. Sezutsu, H.; Yukuhiro, K. Dynamic rearrangement within the Antheraea pernyi silk fibroin gene is associated with four types of repetitive units. J. Mol. Evol. 2000, 51, 329-338. [CrossRef]

10. Hwang, J.; Lee, J.; Goo, T.; Yun, E.; Lee, K.; Kim, Y.; Jin, B.; Lee, S.; Kim, K.; Kang, S.; et al. Cloning of the fibroin gene from the oak silkworm, Antheraea yamamai and its complete sequence. Biotechnol. Lett. 2001, 23, 1321-1326. [CrossRef]

11. Gupta, A.K.; Mita, K.; Arunkumar, K.P.; Nagaraju, J. Molecular architecture of silk fibroin of Indian golden silkmoth, Antheraea assama. Sci. Rep. 2015, 5, 12706. [CrossRef] 
12. Datta, A.; Ghosh, A.K.; Kundu, S.C. Purification and characterization of fibroin from the tropical Saturniid silkworm, Antheraea mylitta. Insect Biochem. Mol. Biol. 2001, 31, 1013-1018. [CrossRef]

13. Hinman, M.B.; Lewis, V.R. Isolation of a clone encoding a second dragline silk fibroin. J. Biol. Chem. 1992, 267, 19320-19324. [PubMed]

14. Gosline, J.M.; Guerette, P.A.; Ortlepp, C.S.; Savage, K.N. The mechanical design of spider silks: From fibroin sequence to mechanical function. J. Exp. Biol. 1999, 202, 3295-3303.

15. Arnott, S.; Dover, S.D.; Elliott, A. Structure of $\beta$-poly-L-alanine: Refined atomic co-ordinates for an anti-parallel beta-pleated sheet. J. Mol. Biol. 1967, 30, 201-208. [CrossRef]

16. Yang, M.; Yao, J.; Sonoyama, M.; Asakura, T. Spectroscopic characterization of heterogeneous structure of Samia cynthia ricini silk fibroin induced by stretching and molecular dynamics simulation. Macromolecules 2004, 37, 3497-3504. [CrossRef]

17. Rousseau, M.-E.; Lefevre, T.; Beaulieu, L.; Asakura, T.; Pezolet, M. Study of protein conformation and orientation in silkworm and spider silk fibers using Raman microspectroscopy. Biomacromolecules 2004, 5, 2247-2257. [CrossRef]

18. Rousseau, M.E.; Beaulieu, L.; Lefèvre, T.; Paradis, J.; Asakura, T.; Pèzolet, M. Characterization by Raman microspectroscopy of the strain-induced conformational transition in fibroin fibers from the silkworm Samia cynthia ricini. Biomacromolecules 2006, 7, 2512-2521. [CrossRef]

19. Lefèvre, T.; Rousseau, M.-E.; Pézolet, M. Protein secondary structure and orientation in silk as revealed by Raman spectromicroscopy. Biophys. J. 2007, 92, 2885-2895. [CrossRef]

20. Boulet-Audet, M.; Vollrath, F.; Holland, C. Identification and classification of silks using infrared spectroscopy. J. Exp. Biol. 2015, 218, 3138-3149. [CrossRef]

21. Guo, C.; Zhang, J.; Jordan, J.S.; Wang, X.; Henning, R.W.; Yarger, J.L. Structural comparison of various silkworm silks: An insight into the structure-property relationship. Biomacromolecules 2018, 19, 906-917. [CrossRef]

22. van Beek, J.D.; Beaulieu, L.; Schäfer, H.; Demura, M.; Asakura, T.; Meier, B.H. Solid-state NMR determination of the secondary structure of Samia cynthia ricini silk. Nature 2000, 405, 1077-1079. [CrossRef] [PubMed]

23. Nakazawa, Y.; Asakura, T. Structure determination of a peptide model of the repeated helical domain in Samia cynthia ricini silk fibroin before spinning by a combination of advanced solid-state NMR methods. J. Am. Chem. Soc. 2003, 125, 7230-7237. [CrossRef] [PubMed]

24. Asakura, T.; Nishimura, A.; Kametani, S.; Kawanishi, S.; Aoki, A.; Suzuki, F.; Kaji, H.; Naito, A. Refined crystal structure of Samia cynthia ricini silk fibroin revealed by solid-state NMR investigations. Biomacromolecules 2017, 18, 1965-1974. [CrossRef] [PubMed]

25. Takahashi, Y.; Gehoh, M.; Yuzuriha, K. Crystal structure of silk (Bombyx mori). J. Polym. Sci. Polym. Phys. 1991, 29, 889-891. [CrossRef]

26. Asakura, T.; Kuzuhara, A.; Tabeta, R.; Saito, H. Conformation characterization of Bombyx mori silk fibroin in the solid state by high-frequency ${ }^{13} \mathrm{C}$ cross polarization-magic angle spinning $\mathrm{NMR}, \mathrm{X}$-ray diffraction, and infrared spectroscopy. Macromolecules 1985, 18, 1841-1845. [CrossRef]

27. Suzuki, Y.; Kawanishi, S.; Yamazaki, T.; Aoki, A.; Saito, H.; Asakura, T. Structural determination of the tandem repeat motif in Samia cynthia ricini liquid silk by solution NMR. Macromolecules 2015, 48, 6574-6579. [CrossRef]

28. Fang, G.; Sapru, S.; Behera, S.; Yao, J.; Shao, Z.; Kundu, S.C.; Chen, X. Exploration of the tight structural-mechanical relationship in mulberry and non-mulberry silkworm silks. J. Mater. Chem. B 2016, 4, 4337-4347. [CrossRef]

29. Malay, A.D.; Sato, R.; Yazawa, K.; Watanabe, H.; Ifuku, N.; Masunaga, H.; Hikima, T.; Guan, J.; Mandal, B.B.; Damrongsakkul, S.; et al. Relationships between physical properties and sequence in silkworm silks. Sci. Rep. 2016, 6, 27573. [CrossRef]

30. Chen, F.; Porter, D.; Vollrath, F. Structure and physical properties of silkworm cocoons. J. R. Soc. Interface 2012, 9, 2299-2308. [CrossRef]

31. Takahashi, Y.; Sumita, I.; Tadokoro, H. Structural studies of polyethers. IX. Planar zigzag modification of poly(ethylene oxide). J. Polym. Sci. Pol. Phys. 1973, 11, 2113-2122. [CrossRef] 
32. Hearle, J.W.S. A critical review of the structural mechanics of wool and hair fibres. Int. J. Biol. Macromol. 2000, 27, 123-138. [CrossRef]

33. Paquin, R.; Colomban, P. Nanomechanics of single keratin fibres: A Raman study of the $\alpha$-helix $\rightarrow \beta$-sheet transition and the effect of water. J. Raman Spectrosc. 2007, 38, 504-514. [CrossRef]

34. Toki, S.; Fujimaki, T.; Okuyama, M. Strain-induced crystallization of natural rubber as detected real-time by wide-angle X-ray diffraction technique. Polymer 2000, 41, 5423-5429. [CrossRef]

35. Kondo, Y.; Hirabayashi, K.; Iizuka, E.; Go, Y. Studies of the fine structure of silk fibroin: (III). Confirmation of the prescence of helical conformation in Anteraea pernyi silk fibroin. Sen-I Gakkaishi 1967, 23, 311-315. [CrossRef]

36. Hirabayashi, K.; Ishikawa, H.; Kakudo, M. Changes in the internal fine structure of silk fibroin by drawing. Sen-I Gakkaishi 1968, 25, 440-446. [CrossRef]

37. Nakazawa, Y.; Bamba, M.; Nishio, S.; Asakura, T. Tightly winding structure of sequential model peptide for repeated helical region in Samia cynthia ricini silk fibroin studied with solid-state NMR. Protein Sci. 2003, 12, 666-671. [CrossRef]

38. Asakura, T.; Ito, T.; Okudaira, M.; Kameda, T. Structure of alanine and glycine residues of Samia c ynthia ricini silk fibers studied with solid-state ${ }^{15} \mathrm{~N}$ and ${ }^{13} \mathrm{C}$ NMR. Macromolecules 1999, 32, 4940-4946. [CrossRef]

39. Balcytis, A.; Ryu, M.; Wang, X.; Novelli, F.; Seniutinas, G.; Du, S.; Wang, X.; Li, J.; Davis, J.; Appadoo, D.; et al. Silk: Optical properties over 12.6 octaves THz-IR-Visible-UV range. Materials 2017, 10, 356. [CrossRef]

40. Moseti, K.O.; Yoshioka, T.; Kameda, T.; Nakazawa, Y.; Tokyo University of Agriculture and Technology, Tokyo, Japan. Structure water-solubility relationship in $\alpha$-helix-rich films cast from aqueous and 1,1,1,3,3,3-hexafluoro-2-propanol solutions of S. c. ricini silk fibroin. Unpublished work. 2019.

41. Bamford, C.H.; Brown, L.; Elliot, A.; Hanby, W.E.; Trotter, I.F. Alpha and beta-forms of poly-L-alanine. Nature 1954, 173, 27-29. [CrossRef]

42. Brown, L.; Trotter, I.F. X-ray studies of poly-L-alanine. Trans. Faraday Soc. 1956, 52, 537-548. [CrossRef]

43. Li, M.; Wu, Z.; Zhang, C.; Lu, S.; Yan, H.; Huang, D.; Ye, H. Study on porous silk fibroin materials. II. Preparation and characteristics of spongy porous silk fibroin materials. J. Appl. Polym. Sci. 2001, 79, 2192-2199. [CrossRef]

44. Nazarov, R.; Jin, H.; Kaplan, D.L. Porous 3-D scaffolds from regenerated silk fibroin. Biomacromolecules 2004, 5, 718-726. [CrossRef] [PubMed]

45. Vollrath, F.; Knight, D.P. Liquid crystalline spinning of spider silk. Nature 2001, 410, 541-548. [CrossRef] [PubMed]

46. Magoshi, J.; Magoshi, Y.; Nakamura, S. Mechanism of fiber formation of silkworm. In Silk polymers, ACS Symposium Series; American Chemical Society: Washington, DC, USA, 1993. [CrossRef]

47. Yoshioka, T.; Tashiro, K.; Ohta, N. Molecular orientation enhancement of silk by the hot-stretching-induced transition from $\alpha$-helix-HFIP complex to $\beta$-sheet. Biomacromolecules 2016, 17, 1437-1448. [CrossRef] [PubMed]

48. Tucker, C.L.; Jones, J.A.; Bringhurst, H.N.; Copeland, C.G.; Addison, J.B.; Weber, W.S.; Mou, Q.; Yarger, J.L.; Lewis, R.V. Mechanical and physical properties of recombinant spider silk films using organic and aqueous solvents. Biomacromolecules 2014, 15, 3158-3170. [CrossRef] [PubMed]

49. Rajkhowa, R.; Kaur, J.; Wang, X.; Batchelor, W. Intrinsic tensile properties of cocoon silk fibres can be estimated by removing flaws through repeated tensile tests. Interface 2015, 12, 20150177. [CrossRef]

50. Offord, C.; Vollrath, F.; Holland, C. Environmental effects on the construction and physical properties of Bombyx mori cocoons. J. Mater. Sci. 2016, 51, 10863-10872. [CrossRef]

51. Hu, X.; Shmlev, K.; Sun, L.; Gil, E.S.; Park, S.H.; Cebe, P.; Kaplan, D.L. Regulation of silk material structure by temperature-controlled water vapor annealing. Biomacromolecules 2011, 12, 1686-1696. [CrossRef]

52. Guan, J.; Porter, D.; Vollrath, F. Thermally induced changes in dynamic mechanical properties of native silks. Biomacromolecules 2013, 144, 930-937. [CrossRef]

53. Freddi, G.; Monti, P.; Nagura, M.; Gotoh, Y.; Tsukada, M. Structure and molecular conformation of Tussah silk fibroin films: Effect of heat treatment. J. Polym. Sci. Polym. Phys. 1997, 35, 841-847. [CrossRef]

54. Yoshioka, T.; Kameda, T. X-ray scattering analyses quantitatively revealed periodic hierarchical structure of polyalanine $\beta$-sheet and non-polyalanine amorphous domains in Antheraea assamensis (Muga) silk. J. Silk Sci. Technol. Jpn 2019, 27, 95-101. [CrossRef] 
Sample Availability: Samples of S. c. ricini LFaq as-cast film and native fiber are available from the authors upon reasonable request.

(C) 2019 by the authors. Licensee MDPI, Basel, Switzerland. This article is an open access article distributed under the terms and conditions of the Creative Commons Attribution (CC BY) license (http://creativecommons.org/licenses/by/4.0/). 